\title{
Indications and Outcomes of Emergency Caesarean Section at St Paul's HospitalMedical College, Addis Ababa, Ethiopia 2017: (Afoul Month Retrospective Cohort Study)
}

\author{
Bizuneh Ayano ${ }^{1 *}$ and Ayana Guto ${ }^{2}$ \\ ${ }^{1}$ Department of Public Health, Salale University, Ethiopia \\ ${ }^{2}$ Medical Doctor at ST Paul's Hospital Medical College, Ethiopia \\ *Corresponding author: Bizuneh Ayano, Lecturer at Department of Public Health, Abebech Gobena campus, Salale University, Fiche Town, Ethiopia
} Submission: 眥 May 08, 2018; Published: 眥 August 20, 2018

\begin{abstract}
Summary
Background: Cesarean Section (CS) rates and their indications vary all over the World. Audit of indications and factors affecting infant and maternal outcome remain an important activity in rationalizing the use of this major procedure in obstetrics practice. Cesarean section (CS) carries a higher maternal morbidity and mortality compared to vaginal delivery. Noresearches have been done on this area.

Objective: To determine the leading indications for ECS and their associated maternal and neonatal outcomes in St. Paul's Hospital Millennium Medical College(SPHMMC).

Methodology: Retrospective facility-based study was used, and data was collected by reviewing the log book of patients who underwent CS operations at St.Paul's Hospital Millennium Medical College (SPHMMC) gyneocology obstetric department from $1^{\text {st }}$ February to $30^{\text {th }}$ May 2017 . The leading indications for Emergency Cesarean Section (ECS) were determined in terms of frequency and percentage. Clinical outcomes of the mothers and the delivered newborns were gauged by morbidity, mortality and survival rates (i.e. within the hospital confinement).
\end{abstract}

Result: A total of 2345, deliveries were conducted, of which 582 deliveries were by cesarean section procedures making the institutional cesarean section rate of $24.8 \%$. Records of patients who underwent Emergency Cesarean section (ECS) were retrieved and comprised the study population $(\mathrm{N}=522)$. Perinatal Asphyxia (PNA) was the most common cause of the neonatal death 6 (42.9\%). Dystocia (26.4\%) emerged as the leading indication for ECS followed by non-reassurance fetal heart rate pattern (NRFHRP) (18.8\%). An association between indications of EC/S,Appearance, Pulse, Grimace, Activity, Respiration(APGAR) scores at $5^{\text {th }}$ minute and fetal outcome with $p$ value of $<0.05$ was observed.

Conclusion: The institutional cesarean section rate is $25 \%$, maternal outcome was favorable with $94.8 \%$ of smooth post operation course and surgical site wound infection was $63.0 \%$ among post operationcomplications that mothers developed.Dystocia (26.4\%) emerged for ECS followed by non-reassurance fetal heart rate pattern (NRFHRP) (18.8\%),Meconium stainedAmniotic fluid (10.7\%)and failed induction(5.4\%). Neonatal outcome with survival rate of 94.1\%.There was an association between indications of emergency caesarean section(ECS), Appearance, Pulse, Grimace, Activity, Respiration(APGAR) scores at $5^{\text {th }}$ minute and fetal outcome with $p$ value of $<0.05$. [Ayano B, Guto A Assessment of indications for emergency cesarean section and its outcomes at St. Paul's Hospital Medical College, Addis Ababa, Ethiopia 2017: (afour-month retrospective cohort study.)]

Keywords: Caesarean section; Pregnancy outcome; Operative delivery; Ethiopia

Abbreviations: AOG: Age of Gestation; ANC: Antenatal Care; APGAR: Appearance Pulse Grimace Activity Respiration; C/S: Caesarean Section; ECS: Emergency Caesarean Section; EONS: Early Onset Neonatal Sepsis; GC: Gregorian Calendar; GYN-OB dep't: Gyneocology Obstetric Department; IUGR: Intrauterine Growth Restriction; MAS: Meconium Aspiration Syndrome; MSAF: Meconium Stained Amniotic Fluid; NICU: Neonatal Intensive Care Unit; NPH: Non Physician Clinician; NRBPP: Non Reassurance Biophysical Profile; NRFHRP: Non Reassurance Fetal Heart Rate Pattern; PIH: Pregnancy Induced Hypertension; PNA: Perinatal Asphyxia; POP: Post Operation; SPHMMC: St Paul's Hospital Millennium Medical College; THAT: Tikuranbessa Teaching Hospital

\section{Introduction}

\section{Background of the study}

Pregnancy and parturition are events of considerable importance in the life cycle of women. Pregnant women may deliver their children via normal spontaneous vaginal delivery or through operational delivery. The quality of obstetric care is reflected on the magnitude of perinatal and maternal mortality and morbidity rates of certain country, which is considered as one of the vital indicators 
of the health status. Although fetal and maternal outcome depends on the quality of care provided starting from the preconception period, the big chunk of it is relied on timely and appropriately carried out intrapartum care. Giving birth is physiological; however, it poses a significant risk to the life and well-being of both the mother and the newborn. From all deliveries, approximately $10 \%$ are considered high-risk, some of which require cesarean section [1].

Caesarean section(CS) is a delivery of a fetus through an abdominal incision (laparotomy) followed by incision of the uterine wall(hysterotomy). CS is further divided into elective and emergency based on whether the operation is scheduled or not and as far as the urgency of operation is concerned.Caesarean section is an operation mainly evolved to save a maternal life during difficult childbirth and recommended when vaginal delivery poses significant risk to mother or baby. Currently it is estimated about 20 million cesarean section (CS) deliveries occur each year in the world. This makes it the most frequent abdominal surgery performed in adults [1-4].

\section{Statement of the problem}

In 1985, the World Health Organization stated: "There is no justification for any region to have CS rates higher than 10-15\%". Two decades later, however, the optimal rate of births by CS remains controversial and currently more cesarean sections are performed in both developed and developing countries andhas been increasing remarkably than the world seem to be justified by established risk factors alone.

In many developed countries, CS rates have increased, and attention has focused on strategies to reduce CS rates due to concern that higher rates do not confer additional health gain but may increase maternal risks, have implications for future pregnancies and have resource implications for health services. Despite this there is a rapid rising of CS delivery rates ranging from $3 \%$ to $50 \%$. This increasing trend has occurred for women of all ages, races, geographic areas and gestational age [1,2].

In 1970, the cesarean delivery rate in the United States was $5.8 \%$. In 2005 , it was $30.2 \%$. It has increased dramatically over the last 47 years to $32.3 \%$ in 2008. Since 1996, the cesarean delivery rate has increased by $50 \%$ [2]. In 2001-2002, the Canadian cesarean section rate was $22.5 \%$. In 2004 , the cesarean rate was about $20 \%$ in the United Kingdom and has been increasing since 1969.Among developing countries like Brazil, cesarean section rates have also increased. In the public health network, the rate reaches $35 \%$, while on the private hospitals network, the rate of cesarean sections is at 79.6\% [1-3]. The dramatic rising of cesarean section has not resulted in significant improvement in neonatal morbidity and mortality, or maternal health. It is well documented that cesarean section carries a much higher maternal mortality and morbidity as compared to a vaginal delivery $[1,2]$.

In 1998 when the cesarean delivery rate was $21.2 \%$ in the United States, the maternal mortality rate was 10 per 100,000 . In 2004 , with a cesarean delivery rate of $29.1 \%$, the maternal mortality rate increased to 14 per 100,000 [2]. With an increase in cesarean delivery, maternal morbidity and mortality has risen. A number of recent studies have documented an increased incidence of placenta previa and accreta with repeated uterine scars. The percentage of peripartum hysterectomy that occurred in a setting of a previous cesarean delivery increased from $27 \%$ to $57 \%$. Of significance was that placenta accreta as an indication of peripartum hysterectomy increased significantly from $5.4 \%$ to $46.5 \%$ [2].

A study published in the February 2007 issue of the Canadian Medical Association Journal found that women who underwent elective CS had an overall rate of severe morbidity of 27.3 per 1000 deliveries compared to an overall rate of severe morbidity of 9.0 per 1000 planned vaginal deliveries. Cesarean section has a much higher mortality for mother and baby in Africa than industrialized countries. Other complications believed to contribute to mortality were intra operative hypotension $(64,75 \%$ of deaths), operative hemorrhage $(45,53 \%$ of deaths), ventilation difficulty $(12,14 \%)$, regurgitation of stomach contents $(11,13 \%)$, pre-eclampsia $(7,8 \%$ of deaths), and difficult intubation (1, 1\% of deaths) [3].

From $23^{\text {rd }}$ June 1992 to 24th September 1993, a prospective study was done in Jimma Hospital to determine the incidence, indications and post-operative complications of caesarean delivery. During the study period 100 mothers were delivered by caesarean section; giving a caesarean birth rate of $8 \%$. There was no maternal death, but the overall morbidity rate was $20 \%$. The causes of morbidity were wound infection (27.1\%), sepsis $(21.4 \%)$, endometritis (33.3\%), haemorrhage (8\%) and wound dehiscence [5]. To reverse the trend of the rising cesarean delivery rate in America, obstetricians planned to reduce the primary cesarean delivery rate, and avoid the performance of a uterine incision unless absolutely necessary for fetal or maternal indications, and for women with one previous low transverse cesareandelivery promote a trial of labor after previous cesarean delivery should be promoted in those women who desire three or more children [1-3].

Ethiopia is one of the countries where cesarean section practice is raising to achieve the Millennium Development Goal(MDG)by giving short trainings for Physicians andnon-physician clinicians (NPC), currentlyreaching46\% in the private for- profit sector and 18\%ingovernment institutions. Across sectional study conducted from 2012-13 at MizanAman General Hospital Southwest Ethiopia, found outthe cesarean section rate was $21.1 \%$. Maternal age, gestational age and the outcome of the new born have significant association with cesarean section and recommended that, the rate of the cesarean section is high.The rate of cesarean section at the hospital should be reduced $[4,5]$.

In general maternal \& neonatal morbidity and mortality in developing countries especially in Sub-Saharan country are very high. Ethiopia as a member of sub Saharan African country contributes a huge number in maternal \&neonatal morbidity and mortality; to reduce this, the country is working hard in a multi directional ways. This includes the accessibility of compressive obstetric care in health institutions, in doing so cesarean section should be performed in those health institutions for scientific 
reason based on the WHO recommendation. Despite post cesarean section high mortality and morbidity rate, few national studies have reported, about Cesarean delivery outcomes on maternal and perinatal health and its impact on the next pregnancy [4-6].

This study tried to over view the frequent emergency indications of cesarean section, contributing factors for cesarean section and its maternal and neonatal outcome during the hospital confinement in St. Paul's Hospital Millennium Medical College (SPHMMC). As this hospital is serving diverse rural and urban population, being one of the referrals and largest hospital where cesarean section is done, the result of this study can be used as a sample for national target population [7]. This study will also be used as baseline for further investigations so that cesarean section should improve and contribute in the reduction maternal \& neonatal morbidity and mortality of the hospital as well as the country.

\section{Significance ofthe study}

Emergency CS has been associated with increased poor maternal and fetal outcomes. Recognition of the factors that predispose emergency CS will help in identifying pregnant women who are at high risk for emergency CS and if possible, alter modifiable factors through education and anticipatory prevention, so as to prevent poor clinical outcomes. The results of this study will benefit hospitals, clinicians, and researchers in anticipating management of the mother and the neonate. It also aims to influence the decision-making among clinicians, with the hope of decreasing maternal and neonatal morbidity and mortality, lowering personal and institutional health care costs.

As there is dearth of local data on this matter, this study tried, to identify the common indications for emergency CS and will fill in the lack oflocal data on emergency CS and could provide a valuable contribution to national data. Recognition of the factors that Predispose for cesarean section will help the health professionals' and the pregnant women to get prepared for the elective cesarean section which has relatively less morbidity and mortality than emergency caesarean section.

\section{Result}

\section{Socio demographic characteristics}

From $1^{\text {st }}$ February to $30^{\text {th }}$ May 2014 a total of 2345 deliveries, were conducted in SPHMMC, out of which 582 were through cesarean section procedures making institutional cesarean section rate of $25 \%$. Out of cesarean section deliveries, records of mothers who underwent ECS and fulfilling the inclusion criteria of the study were retrieved and comprised the study population.

Table 1 shows that majority of women (93.1\%) who delivered through emergency $\mathrm{C} / \mathrm{S}$ belong to the age group of 18 -35 years old. Younger women ( $<18$ years) who underwent emergency CS accounted for only $1.5 \%$ of all emergency cases. Most of the women who underwent EC/S, were primiparous, 307(58.8\%), 190 (36.4\%) were between para2-4 (inclusive). Grandmultiparous women made up only $4.8 \%$ of all EC/S cases.

Table 1: Age group and Parity of mothers who gave birth by ECS at SPHMMC from, $1^{\text {st }}$ February to $30^{\text {th }}$ May in 2017.

\begin{tabular}{|c|c|}
\hline Mothers Gave Birth by ECS & Number \\
\hline Age group (Years) & Number(Percent) \\
\hline$<18$ & $8(1.5)$ \\
\hline $18-35$ & $28(93.1)$ \\
\hline$>35$ & Parity \\
\hline \multicolumn{2}{|c|}{} \\
\hline 1 & $307(58.8)$ \\
\hline $2-4$ & $190(36.4)$ \\
\hline$>4$ & $25(4.8)$ \\
\hline
\end{tabular}

As shown above (Table 1), 307(58.8\%) of mothers were primiparas, thus no previous experience of delivery was recorded. On the other hand, among mothers who previously delivered, route of delivery was not documented for about $70(13.4 \%)$ deliveries, $72(13.8 \%)$ of them delivered vaginally and $60(11.5 \%)$ of them were by single $\mathrm{C} / \mathrm{S}$ while those who delivered by more than one $\mathrm{C} / \mathrm{S}$ were $13(2.5 \%)$. No record of mixed delivery on this study.

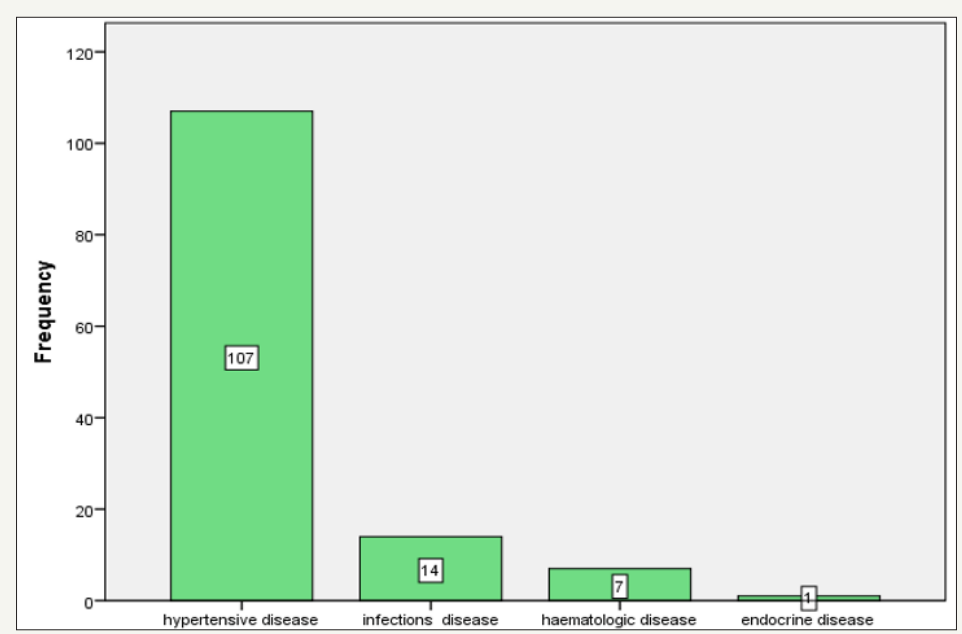

Figure 1: Types of maternal illnesses among mothers who delivered by emergency cesarean section from $1^{\text {st }}$ February to $30^{\text {th }}$ May in 2017 at SPHMMC. 
About $3 / 4^{\text {th }}(75.3 \%)$ of the women who underwent EC/S had no documented, concurrent acute and chronic illnesses with pregnancy. However, $1 / 4^{\text {th }}(24.7 \%)$ of the population had some form of illness during pregnancy. As shown in Figure 1, Hypertensive disease $107(82.9)$ was the most common illness to affect women who underwent ECS. Other disease was infectious disease 14(10.9\%), hematologic disease (anemia) 7(5.4\%) and Endocrine disease (hyperthyroidism) $1(0.8 \%)$. Majority of women $258(49.4 \%)$ gave birth with unknown gestational age. Those, who delivered at term, were 182(34.9\%). Post and preterm deliveries were $47(9.0 \%)$ and $35(6.7 \%)$ respectively. However, after exclusion of births with unknown gestational age, term deliveries were the most common accounting for $67.7 \%$.

\section{Indications for emergency cesarean section}

Dystocia (26.4\%) emerged as the most common indication for ECS. NRFHP was second only to dystocia as the leading indication for ECS accounting for about18.8\%. Furthermore, fetal mal presentation ranked third among the indications for ECS $(12.1 \%)$. $\mathrm{APH}$ was found to be the least indication for EC/S (1.9\%). Notice that dystocia, severe hypertensive disease, fetal malpresentation and others are broad terms and the subdivisions are listed below (Table 2).

Table 2: Indications for emergency cesarean section among deliveries from, ${ }^{1 \text { st }}$ February to $30^{\text {th }}$ May, 2017 at SPHMMC.

\begin{tabular}{|c|c|}
\hline Indications of EC/S & Number(Percent) \\
\hline NRFHP & 98 (18.8) \\
\hline previous c/s & $31(5.9)$ \\
\hline MSAF & $56(10.7)$ \\
\hline Failed induction & $28(5.4)$ \\
\hline multiple pregnancy & $22(4.2)$ \\
\hline Oligo hyderaminous & $33(6.3)$ \\
\hline Prolonged ROM & $5(1.0)$ \\
\hline Post term & $1(.2)$ \\
\hline Cord prolapse & $4(.8)$ \\
\hline Dystocia & $138(26.4)$ \\
\hline arrest of cervical dilatation & $18(3.4)$ \\
\hline arrest of descent & $5(1.0)$ \\
\hline malposition & $51(9.8)$ \\
\hline contracted pelvis & $24(4.6)$ \\
\hline protracted cervical dilatation & $12(2.3)$ \\
\hline Asynclitism & $4(.8)$ \\
\hline deep transverse arrest & $24(4.6)$ \\
\hline hypertensive disease & $24(4.6)$ \\
\hline preeclampsia & $8(1.5)$ \\
\hline eclampsia & $13(2.5)$ \\
\hline HELLP syndrome & $3(.6)$ \\
\hline APH & $10(1.9)$ \\
\hline Placenta prevail totalis & $8(1.5)$ \\
\hline Abruption placenta & $2(.4)$ \\
\hline
\end{tabular}

\begin{tabular}{|c|c|}
\hline Malpresentation & $63(12.1)$ \\
\hline Breech & $32(6.1)$ \\
\hline Transverse lie & $8(1.5)$ \\
\hline Face presentation & $15(2.9)$ \\
\hline Brow presentation & $3(.6)$ \\
\hline Oblique lie & $2(.4)$ \\
\hline Shoulder presentation & $3(.6)$ \\
\hline Others & $9(1.70)$ \\
\hline IUGR & $4(.8)$ \\
\hline NRBPP & $2(.4)$ \\
\hline Transverse vaginal septum & $2(.4)$ \\
\hline Big congenital anomaly & $1(.2)$ \\
\hline
\end{tabular}

Maternal factors and indications for emergency cesarean section: The most frequent indication among term neonates born through EC/S were sever hypertensive disease, cord prolapse (50.0\%)eachfollowed by previous c/s scar (45.2\%). In pre-term neonates however, failed induction (39.3\%) was the most frequent reason for conducting ECS. Post-term was the usual indication of the operation in gestational age $>42 \mathrm{wks}$ (Table 3 ).

Table 3: Indications for EC/S at SPHMMC from $1^{\text {st }}$ February to $30^{\text {th }}$ May 2017 as stratified by AOG.

\begin{tabular}{|c|c|c|c|c|c|}
\hline \multirow{2}{*}{$\begin{array}{c}\text { Indications of } \\
\text { the EC/S }\end{array}$} & \multicolumn{4}{|c|}{ Gestational Age(Wks) } & \multirow[t]{2}{*}{ Total } \\
\hline & $<37 w s$ & $\begin{array}{c}37- \\
42 w k s\end{array}$ & $>42 w k s$ & Unknown & \\
\hline Dystocia & 1 & 48 & 11 & 78 & 138 \\
\hline NRFHP & 4 & 35 & 12 & 47 & 98 \\
\hline Previous c/s & 0 & 14 & 4 & 13 & 31 \\
\hline $\begin{array}{c}\text { Severe } \\
\text { hypertension }\end{array}$ & 3 & 12 & 2 & 7 & 24 \\
\hline MSAF & 0 & 18 & 9 & 29 & 56 \\
\hline $\begin{array}{c}\text { Fetal abnormal } \\
\text { presentation }\end{array}$ & 4 & 24 & 3 & 32 & 63 \\
\hline APH & 0 & 3 & 0 & 7 & 10 \\
\hline Failed induction & 11 & 10 & 1 & 6 & 28 \\
\hline $\begin{array}{c}\text { Multiple } \\
\text { pregnancy }\end{array}$ & 4 & 5 & 0 & 13 & 22 \\
\hline Severe hydrate & 4 & 10 & 3 & 16 & 33 \\
\hline Prolonged ROM & 0 & 1 & 0 & 4 & 5 \\
\hline Post term & 0 & 0 & 1 & 0 & 1 \\
\hline $\begin{array}{l}\text { Cord prolapse } \\
+ \text { cord } \\
\text { appearance }\end{array}$ & 1 & 2 & 0 & 1 & 4 \\
\hline Others & 3 & 0 & 1 & 5 & 9 \\
\hline
\end{tabular}

\section{Clinical outcome ofmothers}

Following emergency cesarean section, majority of mothers (94.8\%) had smooth post op course during the hospital confinement. However, the rest of mothers (5.2\%) had developed post op complications. The causes of morbidity were surgical site wound infection (63.0\%), pulmonary disease (25.0\%), anemia and 
multi system involvement. the leading indications for EC/S among the parturient whodeveloped post EC/S complication were Cord prolapse +cord presentation (25.0\%), dystocia (9.3\%), multiple gestation (9.1\%) and sever hypertensive disease (8.3\%)in the decreasing order respectively. Table 4 frequency and percent of maternal complications according to indications among those who delivered by EC/S at SPHMMC from $1^{\text {st }}$ February to $30^{\text {th }}$ May 2017.

Table 4: Frequency and percent of maternal complications according to indications among those who delivered by EC/S at SPHMMC from $1^{\text {st }}$ February to $30^{\text {th }}$ May 2017.

\begin{tabular}{|c|c|c|c|c|c|}
\hline \multirow{2}{*}{$\begin{array}{l}\text { Indication of The } \\
\text { Current Ec/S }\end{array}$} & \multicolumn{4}{|c|}{ Post Operation Complication } & \multirow[t]{2}{*}{ Total } \\
\hline & Surgical Site Wound Infection & Pulmonary Disease & Anemia & $\begin{array}{l}\text { Multi System } \\
\text { Involvement }\end{array}$ & \\
\hline \multirow{2}{*}{ Dystocia } & 7 & 6 & 0 & 0 & 13 \\
\hline & $53.8 \%$ & $46.2 \%$ & $.0 \%$ & $.0 \%$ & $100.0 \%$ \\
\hline \multirow{2}{*}{ NRFHP } & 3 & 0 & 1 & 0 & 4 \\
\hline & $75.0 \%$ & $.0 \%$ & $25.0 \%$ & $.0 \%$ & $100.0 \%$ \\
\hline \multirow{2}{*}{ Previous c/s } & 2 & 0 & 0 & 0 & 2 \\
\hline & $100.0 \%$ & $.0 \%$ & $.0 \%$ & $.0 \%$ & $100.0 \%$ \\
\hline \multirow{2}{*}{$\begin{array}{c}\text { Severe hypertensive } \\
\text { Disease }\end{array}$} & 2 & 0 & 0 & 0 & 2 \\
\hline & $100.0 \%$ & $.0 \%$ & $.0 \%$ & $.0 \%$ & $100.0 \%$ \\
\hline \multirow{2}{*}{ MSAF } & 2 & 0 & 0 & 0 & 2 \\
\hline & $100.0 \%$ & $.0 \%$ & $.0 \%$ & $.0 \%$ & $100.0 \%$ \\
\hline \multirow{2}{*}{ Failed induction } & 0 & 1 & 0 & 0 & 1 \\
\hline & $0 \%$ & $100.0 \%$ & $.0 \%$ & $.0 \%$ & $100.0 \%$ \\
\hline \multirow{2}{*}{ Multiple pregnancy } & 0 & 0 & 0 & 2 & 2 \\
\hline & $0 \%$ & $.0 \%$ & $0 \%$ & $100.0 \%$ & $100.0 \%$ \\
\hline \multirow{2}{*}{$\begin{array}{l}\text { Cord prolapsed }+ \text { cord } \\
\text { presentation }\end{array}$} & 1 & 0 & 0 & 0 & 1 \\
\hline & $100.0 \%$ & $0 \%$ & $0 \%$ & $0 \%$ & $100.0 \%$ \\
\hline
\end{tabular}

Post operatively, majority $(84.1 \%)$ of women remained in hospital for 4 days or fewer, and 55(10.5\%) stayed for 5-8 days, $25(4.8 \%)$ last $>8$ days and about $3(0.6 \%)$ were not documented. Time spent in hospital varied with indication; women whose indication was failed induction, multiple pregnancy including retained second twin, and severe hypertensive disease were stayed the longest ( $>8$ smooth post op outcome during their hospital confinement (96.1\%). Post op complications tend to be more frequent in those mothers, who had no disease than those who had illness during their days), and severe hydrate, prolonged ROM

Table 5: Post EC/S, maternal outcome according to maternal illness during the pregnancy among mothers who delivered at SPHMMC from February first to May 30/2017.

\begin{tabular}{|c|c|c|c|c|c|}
\hline \multirow{2}{*}{ Maternal Outcome } & \multicolumn{5}{|c|}{ Maternal Illness During Current Pregnancy } \\
\cline { 2 - 6 } & Yes & No & Value & D f & P Value \\
\hline Smooth & $124(96-1 \%)$ & $371(94.4 \%)$ & 0.587 & 1 & 0.444 \\
\hline Developed complication & $5(3.9 \%)$ & $22(5.6 \%)$ & & & \\
\hline
\end{tabular}

\section{Clinical outcomes of neonates}

About 553 neonates were delivered from $522 \mathrm{ES} / \mathrm{C}$ done from February1/2004- May30/2014G.C. These included 491 singletons, and 31 twins. Among these neonates, 22(4.0\%) were stillborn, $531(96.0 \%)$ were born alive, of which $95(18.6 \%)$ were admitted to NICU. From those who admitted to the NICU 15(26.3\%) were died, which is $2.8 \%$ of the neonates who alive immediate after delivery and post-term were those whose high percent of them stayed the shortest $(<5$ days). During the hospital stay period, there was no maternal mortality registered following EC/S.

Table below (Table 5) shows, that most of mothers who had co- morbidities during the pregnancy had smooth post op outcome during their hospital, confinement (96.1\%). Post op complications tend to be more frequent in those mothers, who had no disease than those who had illness during their pregnancy. Furthermore, there was no significant association between the post op outcome and the presence of maternal illness ( $p>0.05$ ).
(Figure 2). MAS 24(25.3\%), pre-term 16(16.8\%), PNA 15(15.8\%) were the frequent, primary indications for the referral. Majority of the case fatalities were registered in patients with PNA 6 (42.9\%), followed by EONS 4(28.6\%).

Neonates having APGAR scores 0 at both 1st and 5thminutes are equal (4.0\%). Majority of neonates have APGAR scores of 7-10 at $1^{\text {st }}$ minute $395(71.4 \%)$ and $5^{\text {th }}$ minute 479 (86.6\%) Table 6. 


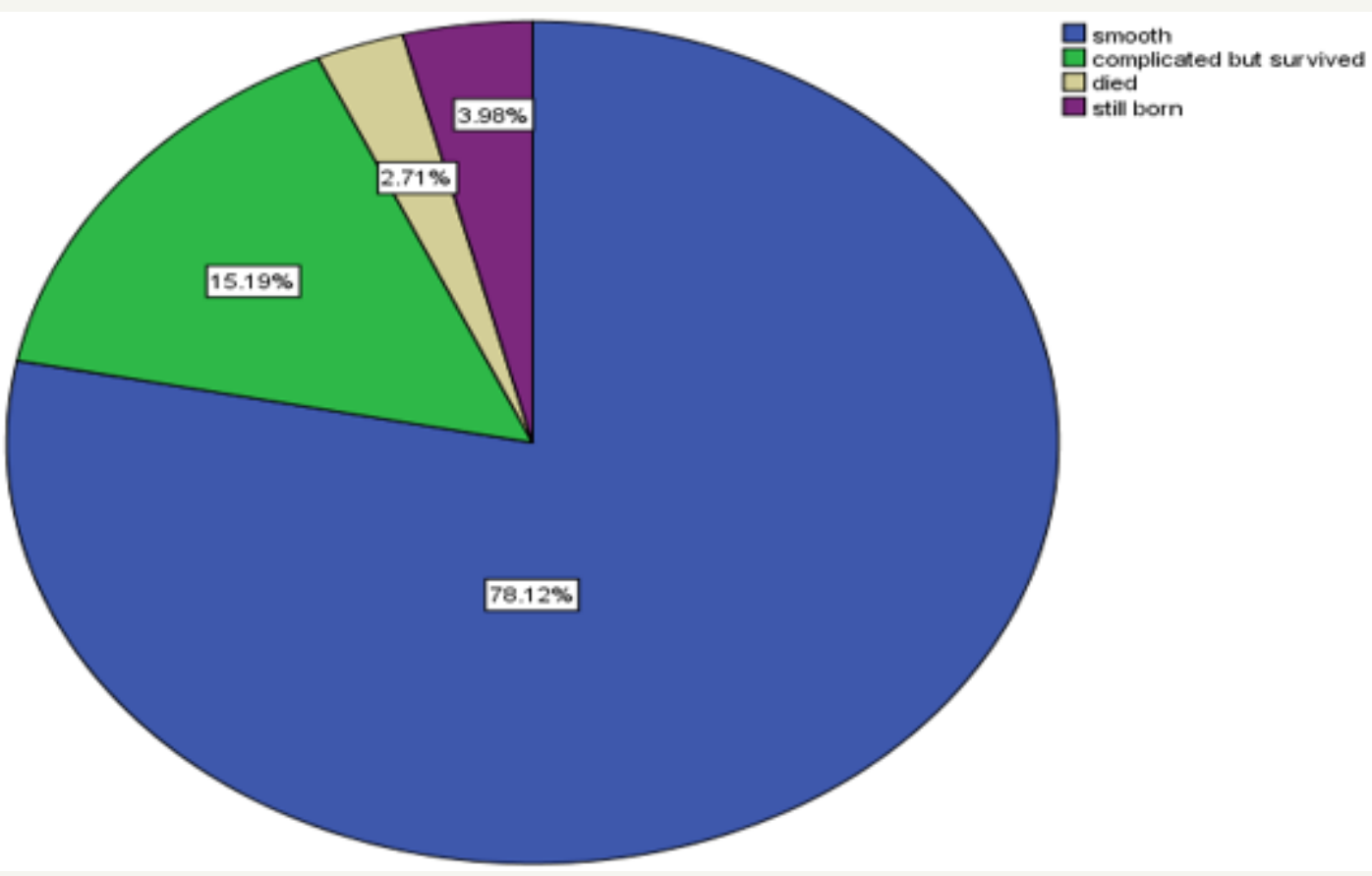

Figure 2: Clinical outcome of neonates delivered by emergency cesarean section from $1^{\text {st }}$ February to $30^{\text {th }}$ May 2017 at SPHMMC.

Table 6: APGAR scores of neonates, at 1 and 5 minutes, after delivered by emergency cesarean section from $1^{\text {st }}$ February to $30^{\text {th }}$ May 2017, at SPHMMC.

\begin{tabular}{|c|c|c|}
\hline APGAR Score & At 1 $\mathbf{s}^{\text {st }}$ Minute & At 5 ${ }^{\text {th }}$ Minute \\
\hline APGAR & Number (Percent) & $22(4)$ \\
\hline 0 & $22(4.0)$ & $9(1.6)$ \\
\hline $1-3$ & $27(4.9)$ & $43(7.8)$ \\
\hline $4-6$ & $109(19.7)$ & $479(86.6)$ \\
\hline $7-10$ & $395(71.4)$ & $553(100)$ \\
\hline
\end{tabular}

Table 7: Emergency cesarean section, outcome of neonates according to age of gestation among deliveries at SPHMMC from $1^{\text {st }}$ February to $30^{\text {th }}$ may $2017(n=553)$.

\begin{tabular}{|c|c|c|c|c|c|c|c|c|}
\hline \multirow[t]{2}{*}{ Outcome } & \multicolumn{8}{|c|}{ Gestational Age(wks) } \\
\hline & $<37$ wks & 37-42wks & $>42 w k s$ & Unknown & Total & $\mathbf{x}^{2}$ & df & $P$ Value \\
\hline Survived & $39(7.6 \%)$ & $180(34.9 \%)$ & $45(8.7 \%)$ & $252(48.8 \%)$ & $516(100 \%)$ & 5.512 & 3 & 0.138 \\
\hline Not survived & $2(5.4 \%)$ & $7(18.9 \%)$ & $3(8.1 \%)$ & $25(67.6 \%)$ & 37 (100\%) & & & \\
\hline Total & $41(7.4 \%)$ & $187(33.8 \%)$ & $48(8.7 \%)$ & $277(50.1 \%)$ & $553(100 \%)$ & & & \\
\hline
\end{tabular}

Below Table 7 illustrates that maximum numbers of post op death were recorded in neonates born to unknown GA 25(67.6\%) out of 37 cases. Pre-term deliveries had the least mortality rate. There was no an association between gestational ages and clinical outcome of the neonates ( $\mathrm{p}=.138$ ) Table 7. Emergency cesarean section, outcome of neonates according to age of gestation among deliveries at SPHMMC from $1^{\text {st }}$ February to $30^{\text {th }}$ May2017 $(n=553)$.
Cord presentation+ cord prolapse (50.0\%), others (25\%) fetal malpresentation (13.4\%) and multiple gestation including retained second twin (9.3\%) were the most common indication for ECS among the unsurvivedneonates. There was an association between indications of EC/S and clinical outcome of the neonates ( $\mathrm{p}=0.007)$ (Table 8 \& 9). 
Table 8: Distributions by mortality and morbidity of neonates after emergency cesarean section, according to age of gestation among deliveries at SPHMMC from $1^{\text {st }}$ February to $30^{\text {th }}$ May, $2017(n=553)$.

\begin{tabular}{|c|c|c|c|c|}
\hline \multirow[t]{2}{*}{ Gestational Age in Weeks } & \multicolumn{4}{|c|}{ Clinical Outcome During Hospital Confinement } \\
\hline & Smooth & Complicated but Survived & Died & Still Born \\
\hline \multirow{2}{*}{$<37 \mathrm{wks}$} & 27 & 12 & 1 & 1 \\
\hline & $65.9 \%$ & $29.3 \%$ & $2.4 \%$ & $2.4 \%$ \\
\hline \multirow{2}{*}{$37-42$ wks } & 165 & 15 & 2 & 5 \\
\hline & $88.2 \%$ & $8.0 \%$ & $1.1 \%$ & $2.7 \%$ \\
\hline \multirow{2}{*}{$>42$ wks } & 36 & 9 & 0 & 3 \\
\hline & $75.0 \%$ & $18.8 \%$ & $.0 \%$ & $6.3 \%$ \\
\hline \multirow{2}{*}{ unknown } & 204 & 48 & 12 & 13 \\
\hline & $73.6 \%$ & $17.3 \%$ & $4.3 \%$ & $4.7 \%$ \\
\hline \multirow{2}{*}{ Total } & 432 & 84 & 15 & 22 \\
\hline & $78.1 \%$ & $15.2 \%$ & $2.7 \%$ & $4.0 \%$ \\
\hline
\end{tabular}

Table 9: Clinical outcome of neonates according to indications of EC/S among deliveries, from $1^{\text {st }}$ February to $30^{\text {th }}$ May 2017 , at SPHMMC.

\begin{tabular}{|c|c|c|c|c|c|c|}
\hline \multicolumn{6}{|c|}{ Indications of EC/S } & \multirow{2}{*}{ Outcome } \\
\hline & Survived (\%) & Not Survived (\%) & p Value & $\mathrm{x}^{2}$ & df & \\
\hline Dystocia & $130(92.9)$ & & $10(7.1)$ & 28.881 & 13 & 0.007 \\
\hline NRFHP & $94(95.9)$ & & $4(4.1)$ & & & \\
\hline Previous $\mathrm{C} / \mathrm{S}$ & $32(100)$ & & $0(0)$ & & & \\
\hline severe hypertensive disease & $28(96.6)$ & & $1(3.4)$ & & & \\
\hline MSAF & $54(100)$ & & $0(100)$ & & & \\
\hline Fetal malpresentation & $58(86.6)$ & & $9(13.4)$ & & & \\
\hline $\mathrm{APH}$ & $9(90)$ & & $1(10)$ & & & \\
\hline Failed induction & $27(96.4)$ & & $1(3.6)$ & & & \\
\hline Multiple pregnancy & $38(88.4)$ & & $5(11.6)$ & & & \\
\hline Severe oligo hyderaminous & $31(93.9)$ & & $2(6.1)$ & & & \\
\hline Prolonged ROM & $6(100)$ & & $0(.0)$ & & & \\
\hline Post term & $1(100)$ & & $0(.0)$ & & & \\
\hline Cord prolapse & $2(50)$ & & $2(50)$ & & & \\
\hline Others* & $6(75.0)$ & $2(25)$ & & & & \\
\hline Total & $516(93.3)$ & $37(6.7)$ & & & & \\
\hline
\end{tabular}

Others*: NRBPP, IUGR, big congenital anomaly, and transverse vaginal septum in labour

Table 10 below demonstrates that majority of neonates, (467) was significance of association between APGAR scores and survival had APGAR scores of $>7$ at $5^{\text {th }}$ minute. Among neonates with APGAR of neonates with $p$ value of $<.05$. scores of $<7$ at $5^{\text {th }}$ minute $53(61.3 \%)$ of them were survived. There

Table 10: Clinical outcome of neonates after EC/S according to APGAR scores at 5 minutes among deliveries from $1^{\text {st }}$ February to $30^{\text {th }}$ May 2017 at SPHMMC.

\begin{tabular}{|c|c|c|c|c|c|c|}
\hline \multicolumn{6}{|c|}{ APGAR at $5^{\text {th }}$ minute } & \multirow{2}{*}{ outcome } \\
\hline Survived & Not Survived & Total & $\mathbf{x}^{2}$ & df & p Value & \\
\hline$>7$ & $463(99.35 \%)$ & $4(.85 \%)$ & $467(100 \%)$ & 111.04 & 2 & 0 \\
\hline$<7$ & $53(61.3 \%)$ & $33(38.4 \%)$ & $86(100 \%)$ & & & \\
\hline Total & $516(93.3 \%)$ & $37(6.7 \%)$ & $553(100.0 \%)$ & & & \\
\hline
\end{tabular}

\section{Discussion}

Since publication of the WHO consensus statement in 1985, debate regarding desirable levels of CS has continued. In this study about 582 cesarean section deliveries were recorded from $1^{\text {st }}$ February to $30^{\text {th }}$ May $2014 \mathrm{GC}$, giving the institutional c/s rate of $25 \%$, of which $90.0 \%$ was EC/S and only $10 \%$ of them had elective caesarean section. In contrast to this a cross-sectional 
study conducted on the prevalence of caesarean section in an urban community of East Delhi and in Madras City in South India, out of 419 caesarean deliveries, reported during the study period;54.9\% were emergency caesarean and $45.1 \%$ were elective caesarean deliveries, which is almost equivalent [3].

In 1993 the Ethiopian institutional cesarean rate was 8\% [5]. Another, study conducted at TATH from 2001 to 2002 GC showed that institutional cesarean rate of $0 \%$, in which $82 \%$ were emergency caesarean section and $18 \%$ had elective caesarean section [6,8]. In 2008 it was reported that the overall Ethiopian institutional cesarean rate was $18 \%$ the highest institutional rate was in the for-profit private sector (46\%), followed by the not-forprofit sector (22\%), and the public sector (15\%) [9]. Another study conducted in Mizan Aman General Hospital Southwest Ethiopia from 2012 to2013 showed that the cesarean section rate of the Hospital was $21 \%[4,9]$.

The trend of cesarean section rate in Ethiopia appears to be increasing like any other part of the World. However, the range of cesarean section rates can be extremely variable from place to place and obstetrician to obstetrician. For example, in different Latin American countries especially in Brazil the rate is very higher. In two different studies done in Brazil the rate of cesarean section is $36.5 \%$ and $43 \%$. In cross sectional study done on factors associated with unjustified Caesarean section in four hospital in Colombia it indicated that the rate of CS was between $42 \%$ and $72 \%[1,7]$. But this figure is higher as compared with the rate that WHO recommended. Although the current institutional C/S rate of $25 \%$ at SPHMMC is higher according to the WHO indicator, this should be seen in the context of the citywide rate, considering SPHMMC is the referral (tertiary) level delivery and the WHO indicator with upper limit of $15 \%$ refers to population (i.e all deliveries in the area) and does not refer to the institutional rate. Accordingly, it is difficult to say whether the institutional rate of $\mathrm{C} / \mathrm{S}$ at SPHMMC, is high, appropriate or low without compressive audit of each case. It would be important to evaluate the trend of $\mathrm{C} / \mathrm{S}$ rates over the years to be able to ascertain increasing trends, factors that may contribute to changes in these rates at this hospital and to institute firm intervention polices to alter this rate. The important consideration is whether the perinatal mortality would be improved as the result of performing more cesarean sections without increased morbidity and mortality of mothers.

\section{Indications for Emergency Caesarean Section}

The commonest indications for performing emergency cesarean section at SPHMMC as shown in Table 2, above were dystocia 138(26.4\%), NRFHRP 98(18.8\%), fetal malpresentation 63(12.2\%),MSAF 56(10.7\%),severe oligohydramnious33(6.3\%), previous c/s scar in labour (5.9\%),failed induction28(5.4\%), sever hypertensive disease $24(4.6 \%)$ and multiple gestation $22(4.2 \%)$. These indications were accounted for $94.5 \%$ of all indications. The results were congruent to those reported around the World. For example, in Zambia dystocia, (30.8\%) fetal Malpresentation (23.8), Repeat CS in Labor (17.3), Non-reassuring fetal tracing (14.1), sever hypertensive disease (4.7) were accounted for $90.7 \%$ of the cesarean section [1,3]. In previously mentioned study, in India, the main indications of caesarean section were fetal distress (22.9\%) followed by post caesarean pregnancies $(21.5 \%)$ and the failure of progression in labour (11.8\%) [3]. A study in Jimma hospital reported thatthe leading indications for caesarean section were cephalopelvic disproportion (44\%), malpresentations and malpositions (21\%), repeat caesarean section (16\%), antepartum haemorrhage $(8 \%)$ and fetal distress (6\%), accounting for $95 \%$ of the indications for caesarean section [5].

However, in both studies quoted above MSAF, sever oligohydramnious and multiple gestations did not feature as prominent indications for EC/S as they do in this study. Dystocia literally means difficult labor and is characterized by abnormally slow progress of labor. According to the American College of Obstetricians and Gynecologists(2003), about 60 percent of cesarean deliveries in the United States are attributable to the diagnosis of dystocia, and thus, its diagnosis has assumed major importance in contemporary obstetrical practice [2,8]. This study identifies dystocia as the leading indication for emergency CS. Dystocia is a general term to encompass the following causes of difficult childbirth: arrest of cervical dilatation, arrest of descent, malposition, contracted pelvis, deep transverse arrest, asynclitism and protracted cervical dilatation. Among these, malposition emerged as the most common form of dystocia that required EC/S (9.8\%) followed by deep transverse arrest and contracted pelvis each accounted for $4.6 \%$.

The identification of dystocia as the leading indication for ECS is supported by other studies at different time. Gifford and colleagues (2000) reported that lack of progress in labor was the reason for 68 percent of unplanned cesarean deliveries for cephalic-presenting foetuses, making dystocia the most common current indication for primary caesarean delivery [8].

A study conducted at the Queen Mother's Hospital, Glasgow, found out that dystocia was the main indication in $16 \%$ of cesarean sections performed in 1991.Similar studies done at Jimma Hospital and Ethiopian national review of caesarean section were reported dystocia as the leading indication of caesarean section in 1993 and 2008 respectively [5,9]. However, in a study done in TAH in 2003 reported that dystocia as the second common indication of $\mathrm{c} / \mathrm{s}$ secondary to repeated cesarean section [6]. However, it is generally agreed that dystocia leading to caesarean delivery is over diagnosed in the United States and elsewhere. Factors leading to increased use of caesarean delivery for dystocia, however, are controversial. Those implicated have included incorrect diagnosis of dystocia, epidural analgesia, fear of litigation, and even clinician convenience [8]. This may be the same reason for high prevalence of dystocia in this study report so that caution and careful evaluation of mother by senior physician before decision for EC/S is recommended.

In this study NRFHRP was cited as the second commonest indication of EC/S 89 (18.8\%). 91.3\% of the cases were in mothers who have hypertensive disease during their pregnancy, 66(67.3\%) of the mothers were primiparious. This is supported by many studies done at different time on indications of EC/S. For instance, 
one study in India reported that the most common indication of repeat cesarean section in emergency group was fetal distress (27.90\%) [10].

Another study done in University of Zambia school of medicineshowed that fetal distress was the third commonest indication of EC/S(15.2\%) of the all indications [1,10]. However, in this study,majority of the neonates with fetal distress(96.0\%) had smooth post EC/S course, there was only $2.0 \%$ neonatal death and $2.0 \%$ still birth. Cesarean section is done for indication of the fetal distress based on the characteristics of the fetal heart rate pattern by pinard stethoscope or CTG, however as reviewed by Literatures, use of electronic fetal heart rate monitor intends to increase caesarean section rates [8,11]. Moreover, Although EC/S done for fetal distress, it was noted that majority of the neonates had APGAR scores of $7-10,61.0 \%$ and $86.1 \%$ at 1 st and 5 th minutes respectively and no APGAR scores of $<4$ at 5 th minute except the still born cases.

Fetal malpresentation, Which includes breech presentation, oblique lie, transverse lie, face and persistent brow presentation ranked $3^{\text {rd }}$ as the most common indication for emergency $\mathrm{C} / \mathrm{S}$ accounting for $12.1 \%$ of all indications. About 32(50.8\%) of the maternal subjects to which EC/S was done for fetal malpresentation were nulliparous and more than half of the malpresentation 32(50.8) was breech. This finding is supported by the study of Lieberman et al which noted that nulliparous women are of increased risk of breech presentation $[3,4,12]$. Ethiopian national review of C/S rate (2008) was put fetal malpresentation at $3^{\text {rd }}$ rank (14\%), for C/S following dystocia (34\%) and fetal distress (15\%), respectively, which is congruent to this study finding [9]. However, the high rate of malpresentation (specially breech) in nulliparous is controversial to the study breech presentation is increases as parity increases.

MSAF was ranked as the fourth leading indication of EC/S(10.7\%). Me conium, usually pass in term and post term pregnancies. Its passage indicates underlying fetal distress (asphyxia). Although there is no agreed international standard classification of indications for cesarean delivery [1,2] because definitions are not standardized, and indications are multiple or interrelated, emergency cesarean section for an indication of MSAF is usuallydone for GIIIMSAF, this is the subjective judgment which may vary from individual to individual, making decision for $\mathrm{c} / \mathrm{s}$ difficult or inappropriate decision to do EC/S. So as recommendation, it is better not to relay only on MSAF for $\mathrm{C} / \mathrm{S}$ rather than on fetal clinical features and underlying causes of meconium passage. Repeat CS ranked fifth as the most common indication for ECS (5.9\%). Previous studies showthat repeat CS is the leading indication for ECS. Repeat CS, as one of the indications for ECS, registers an increasing trend $[6,13]$.

A national review of C/S rate done in Ethiopia in 2008G.C reported that the overall $\mathrm{EC} / \mathrm{S}$ rate done for indication of repeat $\mathrm{C} / \mathrm{S}$ was $11 \%$, in all facilities, $7 \%$ in public sector and $27 \%$ in privatefor profit sector [9].Another study done in Nigeria reported that
Previous caesarean section was the second most common maternal indication (17.6\%). In Jimma university it was reported that c/s for indication of repeat $\mathrm{C} / \mathrm{S}$ was as high as $16 \%$, [5].Previous caesarean section was said to constitute the highest single indication for repeat section because obstetricians still regard vaginal birth after previous caesarean section as a high-risk option. Trial of labor under close monitoring in carefully selected patient is now increasingly being advocated and it is reported that $64.8-86.0 \%$ of patients with a caesarean section who were allowed for trial of labor delivered without any complication [10].

The increasing trend for repeat CS may be explained, by an early onset of labor prior to theschedule or due to inappropriate ANC and most women presented at the emergency room with uterine contractions, bleeding and ruptured membrane, imposing to rush for EC/S. However in this study rate of repeat C/S for previous C/S scar was low compared to other reports, this low number may be explained by the reason that elective cesarean section was excluded from the data and most of the mothers with previous C/S scar are usually scheduled for elective operation as they have better back ground information the route of delivery than those with no history of previous $\mathrm{c} / \mathrm{s}$.

\section{Maternal Factors and Indications for Emergency Cesarean Section}

This study show that majority of maternal subjects (93.1\%) belong to the age group, 18-35 years old. The high rate of ECS among this age group is expected because majority of child births occur within this age range and perhaps, indicate the positive attitude and practice towards family planning. A study done at Mizan Aman General Hospital bench maji zone southwest Ethiopia (2013), was reported, that mothers whose age is between 20-24 are 3.2 times more likely to undergo Cesarean section as compared with those age is between 15-19 years. Those whose age was between 2534 years are 3.6 times more likely to undergo Cesarean section as compared with those whose age was between 15-19 years. Mothers whose age was 35 and above were 10 times more likely to undergo CS as compared with those,age between 15-19.Another study demonstrated that Half of the women who gave birth after 28 weeks of gestational age being primiparous, $7.8 \%$ being grand multifarious and $80.2 \%$ being in the age range of $20-34$ years, which supports the current study $[4,6]$.

Al Nuaim et al. [14]. observed the same trend in the rate of emergency CS in this age group. They noted a higher incidence of emergency CS (79\%) in younger age groups ( $<35$ years) compared with $21 \%$ in older patients ( $>35$ years) about $5.4 \%$ of the parturient who underwent ECS belong to the $>35$ years age group (3).In contrast to this study Several studies have demonstrated that high incidence of emergency CS is associated with advancing age. This may be due to an increased incidence of placental abruption, placenta previa, breech presentation, preterm labor, and multiple gestation in parturient of advanced maternal age. Advanced maternal age is also associated with increased incidence of breech presentation and fetal macrosomia $[1,3,9,13,15]$. 
Parturient within the $<18$ years old age group who delivered through ECS accounted for only less than 1.5\% of ECS deliveries. Similar finding reported in West Visayas State University, Philippines supports this study, which reported that matters whose age $<18$ years old were accounted for only $<1 \%$ of the EC/S (3). These finding may be due to the fewer pregnancies and deliveries in this age group. However without distribution of ages of all women who, delivered through any mode of delivery during the study period, it is difficult to comment C/S rate of different age group.

Result of this study show that with increasing parity, the frequency of ECS deliveries decreases it was $58.8 \%$ in primiparious, $36.4 \%$ in multifarious and only $4.8 \%$ of the grand multifarious deliveries. This finding agrees with the result of the study done by $\mathrm{Al}$ Nuaim et al. [14]. where they demonstrated a statistically significant association between low parity and ECS sealed further the strong relationship between low parity and emergency CS when they reported that increasing number of deliveries was associated with a decrease in risk for both elective and emergency CS [16]. In primipar as, dystocia, NRFHP, sever hypertensive disease failed induction and MSAF were the most common indication of the EC/S in the increasing order respectively while repeat CS is the most common indication for multifarious. Repeat CS is highest among women who had 2-4 previous deliveries and a sharp decline is observed with increasing parity. Similar study was also reported by one study done in Phillipins, supporting the idea of this study [3]

Primiparas are known to have a higher incidence of severe hypertensive disease compared to the multiparas women. As expected hypertensive disease featured as a cause for cesarean section more often in those who had been primiparas as seen in this study. The higher incidence of the fetal distress as indication for EC/S was probably common in primiparas in association with more prolonged labour and oxytocin augmentation, in comparison with multifarious women in whom, labour is generally shorter. Similarly the high rate of dystocia in primiparious women can be explained by the factor untried pelvis compared to the paras. Among grandmultiparas, APH was the most common indication for $\mathrm{EC} / \mathrm{S}$. This is may be due to an increasing risk of placentalprevia and placental abruption as parity increases due to multiple repeated scars to uterine wall.In contrast to this result in one study it was reported that fetal malpresentation was the most common indication for ECS among grandmultiparas $[3,17]$.

During, review of maternal chartsgestational age was unknown in $49.4 \%$ cases of emergency cesarean section (522 cases). In contrast to this one study in Zambia reported that only $11 \%$ of pregnancies did not know their gestational age (221 of the 1880 cases).Although it is expected as many women may not have known for certain the date of their last menstrual period, this number is too much, and may be unacceptable as current national, ANC follow up status is expected to be high and gestational age is the crucial factor in decision making to do elective $\mathrm{C} / \mathrm{S}$, maternal readiness for delivery and post $\mathrm{C} / \mathrm{S}$ immediate neonatal care. In those whose Gestational age known majority of them were term(34.9\%), followed by post term (9\%) and pre-term as the list accounting for
$6.7 \%$. However, after exclusion of births with unknown gestational age, term deliveries were the most common accounting for $67.7 \%$.

This finding is similar with the retrospective analysis of 25 consecutive emergency cesarean sections for umbilical cord prolapse, which showed that out of twenty-five, 17 patients were born term (68\%). The most frequent indication among term (50.0\%) neonates born through ECS were sever hypertensive disease, cord prolapse + cord presentation followed by previous c/s scar (45.2\%). However, in pre-term neonates, failed induction $(39.3 \%)$ was the most frequent reason for conducting ECS. Postterm was the usual indication of the operation in gestational age $>42 \mathrm{wks}$ ).

\section{Clinical Outcome of Mothers}

As demonstrated in the result section there was no maternal death recorded during within hospital confinement. Majority of parturient $(94.8 \%)$ had smooth post op coarse while $5.2 \%$ of mothers were complicated. This is similar to the study reported in Jimma University, which demonstrated that there was no maternal death out of 100 mothers who have undergone caesarean section from $23^{\text {rd }}$ June 1992 to 24th September 1993, but the overall morbidity rate was $20 \%$ [5]. There are also studies illustrating, high survival rates of mothers following both emergency and elective cesarean sections. For example, one study in Philippines showed, the Survival rate for ECS is relatively high (97.4\%) [3]. Another prospective observational study of 8070 cesarean sections in Malawi put the maternal Mortality rate was less than $1 \%$. Some of the reasons cited by Obstetrical and Gyneocological Society for the increasing survival rate is the increasing safety of the procedure due to antibiotics; availability of blood transfusions; better anesthesia and the physicians high intent to deliver a healthy or undamaged baby and leave a healthy mother, when done for complications occurring during pregnancy and labor $[1,3]$.

On the other hand, a study conducted at TAH, reported, that out of 318 , cesarean sections there were five $(15.7 \%)$ maternal deaths. The main cause of maternal death was failure to control bleeding during the caesarean section. It was suggested that, these were preventable deaths in experienced hands [6]. As I tried to mention above, about 27(5.2\%) of mothers developed post op complications during the period of hospital confinement. The causes of morbidity were surgical site wound infections (63.0\%), pulmonary disease (25.9\%), anaemia $(3.7 \%$ and multi system involvement $(7.4 \%)$. This is lower than the one in Jimma University which, reported morbidity rate of $20 \%$. But the most common cause of the morbidity was wound infection (27.1\%), which is consistent with the current study. Other causes of morbidity were sepsis (21.4\%), endometritis (33.3\%), haemorrhage (8\%) and wound dehiscence (10\%) [5]. A retrospective cohort study, conducted in Chinain 2012 to determine maternal and neonatal outcome associated with cesarean section done, reported that, post opmaternal morbidity was still, high like increased blood loss (14\%), uterine incision extension (8\%), atomic PPH (8\%), prolonged bladder catheterization (38\%), wound infection (16\%) and postpartum fever (12\%)[10]. 
The lower figure of post $\mathrm{C} / \mathrm{S}$ maternal complication in this study can be explained by the increasing national ANC coverage and early treatment of the maternal co morbidities and increased quality of intra-operative and post-operative care and use of prophylactic antibiotics and blood transfusion. However, in contrast to complications seen in other studies, surgical site wound infection was found to be significantly high, in this study, which rises question about extent of sterility of the surgical procedures, though other factors like maternal, weight, nutritional status, anemia, can contribute for post operation infections complication. Furthermore, it's difficult to draw conclusion about the fate of mothers post operatively since this study was assessed only the maternal condition during hospital stay period which was as short as two days and most of them stayed for $<5$ days. So as recommendation it is better to conduct another study focusing on the post EC/S maternal outcome for extended period of time. Cord prolapse +cord presentation (25.0\%), Dystocia (9.3\%), multiple gestation (9.1\%) and sever hypertensive disease (8.3\%) were the leading indications for ECS among the parturient who, developed post ECS complication.

In this study maternal illness during pregnancy, found to have non, significant impact on post EC/S maternal outcome, showing that most of the mothers(96.1\%) who had co-morbidities during pregnancy, had smooth post op course. There was no association between maternal illness and post op complication with $(\mathrm{p}=.444)$. This result may, explains good prenatal control of the co-morbidities and improved ANC quality.

Regarding the duration of hospital stay post operatively, different studies shows that compared to the elective C/S extended hospital stay is found more in emergency caesarean section group. This is due to the increased post-operative morbidity associated with emergency caesarean section than the elective $c / s[9,11]$. In this study a total, of $439(84.1 \%)$ of women remained in hospital for 4 days or fewer, and 55(10.5\%) stayed for 5-8 days, 25(4.8\%) last $>8$ days and about $3(.6 \%)$ were not documented.

Time spent in hospital varied with indication; women whose indication was failed induction, multiple pregnancy, and severe hypertensive disease were stayed the longest ( $>8$ days). As mentioned in the indications of EC/S and its outcome multiple gestation and sever hypertensive disease were listed as the primary indications with post $\mathrm{C} / \mathrm{S}$ complications, so that prolonged hospital stay is expected in these cases. On other hand extended hospital stay in mothers with failed induction may be due to the presence of the underlying factor for the initiation of induction or do to development of complication specially infection because of repeated per vaginal examination of the mothers is common in these cases to evaluate for progression of labour. On contrary to the above, severe oligohydraminous, prolonged ROM and post term were those indications, with shortest period of hospital stay $(<5$ days).

A national review of $\mathrm{C} / \mathrm{S}$ rate in Ethiopia in 2008demonstrated that in total, $26 \%$ of women remained in hospital for 3 days or fewer, and $65 \%$ stayed for 4-8 days women whose indication was
CPD stayed the longest (6.8 days on average) and those who were HIV-positive stayed the shortest (3 days)(9).In comparison to this report, duration of hospital stay was shorter in the current study, which may explains the above sited lower post op complications of mothers.

\section{Clinical Outcome of Neonates}

Taking in to consideration multiple pregnancies, about 553 neonates were delivered from $522 \mathrm{ES} / \mathrm{C}$. Among these neonates, $22(4.0 \%)$ were still born, and 531(96.0\%), were born alive, of which $95(18.6 \%)$ were admitted to NICU. From those who admitted to the NICU, $15(26.3 \%)$, were died, which is $2.8 \%$ of the neonates who alive immediate after delivery. MAS 24(25.3\%), pre-term 16(16.8), PNA 15(15.8) were the frequent, primary indications for the referral. Majority of the case fatalities were registered in patients with PNA 6(42.9\%), followed by EONS4 (28.6\%).

Table 9 illustrates that cord prolapsed + cord presentation was the indication in which half $(50.0 \%)$ of the neonatal outcome was poor (2deaths out of 4cases). Others (NRBPP, IUGR, big congenital anomaly, and transverse vaginal septum in labour) was ranked second accounting for (25\%) of death. Fetal malpresentation (9cases out of 67$)(13.4 \%)$, multiple gestation including retained second twin (9.3\%), and APH (10\%) were also the most commonindications of new born death. In contrast to this, Previous $\mathrm{C} / \mathrm{S}$ scar, prolonged $\mathrm{ROM}$, and post term were among the indications for ECS following which all neonates were survived 100 . There was significance of association between indications of EC/S and survival of neonates with $\mathrm{p}$ value of $<0.05$.

Similar study was reported in Zambia, explaining that out of 139 still born (including ruptured uterus) $88.5 \%$ of still born after uterine rupture, $16 \%$ after $\mathrm{APH}, 12.6 \%$ after fetalmalpresentation [18]. However, in this, study cases of uterine rupture were excluded from the criteria because, even though it is an emergency, operation to salvage either fetus or mother or both, basically it is laparotomy and not considered as cesarean section.

Even though information regarding time of fetal death was not available, emergency cesarean section was done trying to salvage fetal live specially in indications that does not dangers maternal live other than neonatal live, like cord presentation and cord prolapse, or EC/S may do for still fetus diagnosed before surgery to salvage life of mother like in case of APH. However, it is not unexpected in some cases that the diagnosis of intrauterine death may have been missed or that the severely distressed foetuses, die between the time of diagnosis and delivery, which needs more attention and evaluation by experienced hand possibly by obstetric sonography before decision for $\mathrm{C} / \mathrm{S}$, so that maternal future compromise will be salvaged. Furthermore, under indications of EC/S above, we have seen that majority of the neonates with fetal distress (96.0\%) had smooth post EC/S course, there was only $2.0 \%$ neonatal death and $2.0 \%$ still birth. In contrast to the current result a study conducted in TAH was reported that, most of the neonates that bornafter presented with NRFHRP had low APGAR scores at the 1st minute $(61.4 \%)$ [6]. 
The fetal outcome was poor in those whose gestational age was unknown. It was noted that out of 37 cases of neonatal death $25(67.6 \%)$ of them were from those with unknown GA. Post op complication, was seen to be the highest among the pre-term newborns, accounting for $(31.7 \%)$ of the pre-term newborns. This high rate of complications with prematurity may be as the result of the effect of pre-term neonatal complications like HMD, hypothermia or hypoglycemia or it could be due to the underlying, factors which imposed the pregnancy for termination. Despite the high rate of complications, the overall survival rate of pre-term deliveries was good (95.2\%), of this, $29.3 \%$ of them were those who admitted to NICU. This may suggest the improved quality of neonatal care and giving more attention for per-term neonates than others, by obstetrics team and NICU unit. On the other hand, neonates who born at term were among those with low rate of still born and neonatal death with $88.2 \%$, of smooth post EC/S outcome and overall survival rate of $96.2 \%$, supporting the idea of delivery at term is the safest period. However, there was no an association between gestational ages and clinical outcome of the neonates ( $p=$.138). It was shown that Table 10 majority of neonates 467 had APGAR scores of $>7$ at $5^{\text {th }}$ minute of which $99.3 \%$ of them were survived with only 4 neonatal deaths.On the other hand, among neonates with APGAR scores of $<7$ at 5 th minute $38.7 \%$ of them were not survived.

This finding signifies that the APGAR score at 5 minutes is a better predictor for neonatal survival than the APGAR score at 1 minute. This finding is congruent with the study of OMING, et al. who found out that a higher mortality rate is recorded among neonates with low (0-3) APGAR scores of at 5 minutes (88.8\%) with its counterpart at 1 minute $(9.68 \%)$. The same is true in neonates who with average APGAR scores (4-6 at) 5minutes where in $40 \%$ died as compared to its counterpart at 1 minute where in $9.7 \%$ of the neonates died.

Another study by Nuaim et al. [14] suggested that, those neonates born through ECS with an APGARscore of 0-3 at birth had the highest risk of neonatal death. Furthermore, the risk of neonatal death in term infants was 0.2 per 1000 for those with scores of 0 to 3 at birth $[3,18]$. As expected, low mortality rate was seen among neonates with high APGAR scores [7-10] at 1Minute (0\%) and 5 minutes $(0.4 \%)$. In this study there was significance of association between APGAR scores at $5^{\text {th }}$ minute and survival of neonates with $\mathrm{p}$ value of $<0.05$.

Generally, in this study, the overall neonatal death rate was $6.9 \%$ making survival rate of $94.1 \%$. This is more, better than the one reported in 2008, Ethiopian national review of cesarean section rate, which found out that, $81 \%$ of the cases reviewed had a live birth, $14 \%$ had a stillbirth or early neonatal death, and $5 \%$ had no fetal outcome information. Fetal outcomes were poorer among women who underwent emergency cesarean (16\%) than among women who had an elective cesarean (7\%) and among women whose indications for cesarean were breech or fetal distress [19]. On the other hand, one study in Philippine's, wrote that the success rate in delivering a live neonate by emergency cesarean section was as high as $(97.2 \%)$.

\section{Limitations of the Study}

A. Since the study design was retrospective mothers and neonates whose medical records, were not fully documented or not found were automatically removed from the study.

B. Clinical outcomes of mothers and neonates are limited by intra hospital confinement of short duration.

C. The duration of labour the time interval between decision for EC/S and start of operation were not determined.

\section{Conclusion}

The rate of the cesarean section was found to be high as compared with the findings of other Ethiopian institutional cesarean section rates and WHO cesarean section rate recommendation. This study identifies dystocia as the leading indication for emergency CS, followed by NRFHRP. All mothers were survived post operatively. Surgical site wound infection was found to be the most common, among post operation maternal complications. Neonatal outcome was seen to be better than other similar studies with survival rate of 94.1\%.Cordprolapsed+cord presentation was the indication in which high number of neonatal death was seen. PNA was found to be associated with high neonatal death among neonatal complications.

\section{Recommendation}

The rate of cesarean section at the hospital is high according to WHO recommendation. However, it is difficult to say whether the institutional rate of C/S at SPHMMC, is high, appropriate or low since it serves as referral hospital. It would be important to evaluate the trend of C/S rates in other similar referral institutions to be able to ascertain increasing trends, factors that may contribute to changes in these rates to institute firm intervention policies in order to alter this rate.

Proper and early started ANC follow up should be encouraged by the Government and other concerning body having in mind, the significance of knowing gestational age, in decision making to do elective $\mathrm{C} / \mathrm{S}$.

A longer study period may establish patterns of post op outcome of mothers and neonates over the years.

Although EC/Swas done for indication of NRFHRP in $18.8 \%$ ofmothers it wasnoted that majority of the neonates (86.1\%) had APGAR scores of $7-10$, at $5^{\text {th }}$ minutes and there was only $4.0 \%$ neonatal death. So it is better to regularly follow and evaluate fetal heart beat before decision for EC/S.

\section{Competing Interests}

The Authors declare that they have no competing interests.

\section{Data Materials Section}

The necessary Data and materials are available with reasonable request.

\section{Funding}


Funding source was from ST. PAUL'S HOSPITAL MEDICAL COLLEGE, ADDIS ABABA. The only funding body in the design of the study and collection, analysis, and interpretation of data and in writing the manuscript.

\section{Consent to Publish}

The Authors declare that they have consent and right to publish this research. Consent for publication of images may not be required. The final decision on whether consent to publish is required lies with the Editor.

\section{Authors Contributions}

The Authors are Bizuneh Ayano and Dr. Ayana Gutoboth of them developed research proposal, searching for funding, data collection, controlling data collectors, supervising, compiling, and organizing, finally research reporting and defense. Additionally Bizuneh Ayano has also prepared research manuscript.

\section{Acknowledgement}

I am grateful to express my heartfelt appreciation and thanks to my advisors Dr.YosephWorku and Dr. Tadesse Urge who have given me unreserved advices and made constant follow up from the start to the completion of this research.

My especial thank goes to the SPHMMC staffs of Public health and Gynecology departments as well as to the Hospital Academic and research wise provost and the Head of Records Section who made me access to all requested information, and use of possible resources. Finally, I am grateful to all the data collectors for their hard work and patience in obtaining necessary information.

\section{Ethics Approval}

This research was done with approval and consent form from Ethiopian Science and Technology Commission Health Department; National Health Research Ethics committee and University permission. All health researches involving human participants must be subjected to independent ethics review and this should be conducted by a health research ethics review committee.

\section{Autonomy}

This principle aspires to protecting the multiple and interdependent interests of the person from bodily to psychological to cultural integrity. It refers to the obligation on the part of the investigator to respect each participant as a person capable of making an informed decision regarding participation in the research study.

\section{Informed Consent}

Research participants or persons giving proxy consent cannot give full informed consent unless the consent form contains adequate information. And the information on what the study entails to the individual as a result of participation in the study shall be expressed in a language that is understandable to the participant. Generally, the consent form should explicitly indicate the followings: purpose of the research, its duration, procedures, foreseeable risks and discomforts, extent of confidentiality, expected benefits to the participants as well as the community at large, compensation to possible injury and the full address of appropriate ethics monitoring body. Research participants are free to withdraw from the study any time they want.

\section{Confidentiality}

The researcher(s) shall assure that information that has been obtained in the course of investigation remains confidential to protect participants from possible harm at the revelation of such information. Data unlinked from individual(s) or group(s) does/do not jeopardize confidentiality. The privacy of individual participant needs to be kept throughout the investigation by the researcher(s).

\section{Beneficence}

Refers to the obligation on the part of the investigator to attempt to maximize benefits for the individual participant and/ or community, while minimizing risk or harm to the individual. An honest and thorough risk/benefit calculation must be performed.

\section{Justice}

Justice connotes fairness and equity, and concerns in the distribution of benefits and burdens of research. It also demands equitable selection of participants, i.e., avoiding participant populations that may be unfairly coerced into participating, such as prisoners and institutionalized children. Injustice may arise when selecting participants only from a specific socio-economic class, age, sex, racial, cultural, and institutional make up.

\section{Annexes}

Annex I: English version participant information sheet and consent form

Consent form for the study entitled to Assessment of indications for emergency cesarean section and its outcomes at St. Paul's Hospital Medical College, Addis Ababa, Ethiopia.

\section{Consent Form}

\section{Information to study participants}

Title of the study: Assessment of indications for emergency cesarean section and its outcomes at St. Paul's Hospital Medical College, Addis Ababa, Ethiopia.

\section{Introduction}

Greeting--

My name is and I am working after graduated my master's degree in Public health, FromUniversity; now I am Lecturer at Addis Ababa University Selale campus. I am planning to conduct study on Assessment of indications for emergency cesarean section and its outcomes at St. Paul's Hospital Medical College, Addis Ababa, Ethiopia.

Whatever information you would provide will be kept confidential. We will not record your name on the questionnaire. 
Your name will not be identified in any output of this study. You have full right to withdraw from this study at any time without a need to mention the reason why you wanted to withdraw. We value your input to make this study a successful one.

\section{Purpose of the study}

The main purpose of this study is to assess indications for emergency cesarean section and its outcomes at St. Paul's Hospital Medical College, Addis Ababa, Ethiopia. The information that you will provide us will help us to improve emergency cesarean section and its outcomes and prevention service program in the study area in particular and in Ethiopia in general.

\section{Procedures}

If you agree to participate in this study, we will interview you about emergency cesarean section, its outcomes and prevention.

\section{Potential risks and discomfort of being in the study}

By participating in this research project, you may have some discomfort. There are no or minimal anticipated risk but taking time about 30 minute for interview.

\section{Benefits of being in the study}

There may not be direct benefits to you for giving us information for the study. In the future ifcesarean section and its outcomes prevention and control service coverage is increased you have in directly benefit due to healthy condition of you and your community.

\section{Confidentiality and privacy protections}

The records of this study will be stored securely and kept confidential. All publications will exclude any information that will make it possible to identify you as a subject.

\section{Contacts and questions}

If you have any questions about the study please ask me now. If you have questions later, want additional information, or wish to withdraw call the researcher conducting the study. If you have questions about the research please contact Bizuneh Ayano and Dr. Ayana Guto who are principal investigators of this study in the University of Addis Ababa at +251(0)911381859 and +251913386757 .You are making a decision about allowing participating in this study. Your signature below indicates that you have read or has been read to you the information provided above and has decided to participate in the study. If you later decide that you wish to withdraw to participate in the study, simply tell me. You may discontinue your participation at any time.

Name of study participant:

Signature: Date:

Name of data collector Signature Date

\section{References}

1. WHO (2007) Rates of caesarean section analysis of global, regional and national estimates. Paediatr Perinat Epidemiol 21(2): 98-113.
2. Howard B (2011) The rising caesarean delivery rate in America. The American College of Obstetricians and Gynecologists 118(3): 156-172.

3. Omamalin NG. Indications for emergency caesarean section and associated clinical maternal and neonatal outcomes at WVSU-MC: a three-year retrospective study. College of Medicine, West Visayas State University, Iloilo City, Philippines, USA, (unpublished).

4. Hordofa G, Ashenafi S (2014) Caesarean section and associated factors at MizanAman General Hospital Southwest Ethiopia. Journal of Gynecology and Obstetrics 2(3): 37-41.

5. Ali Y (1995) Analysis of caesarean delivery in Jimma Hospital, Southwestern Ethiopia. East Afr Med J72(1): 60-63.

6. Tadesse E, Adane M, Abiyou M (2003)Caesarean section deliveries at Tikur Anbessa Teaching Hospital, Ethiopia. Ethiop J Health Dev 2(3): $37-41$

7. Gomez OL, Carrasquilla G (1999) Factors associated with unjustified Caesarean section in four hospitals in Cali, Colombia. Int J Qual Health Care 11(3): 385-389.

8. Steven L (2005) Williams obstetrics. ( $22^{\text {th }}$ edn), McGraw-Hill, USA.

9. St. Paul's Hospital Millennium Medical College Curriculum Report. Annie Porter Fall 2012.

10. Fesseha N, Getachew A, Hiluf M, Gebrehiwot Y, Bailey P (2011) A national review of cesarean, delivery in Ethiopia. International Journal of Gynecology and Obstetrics 115(1): 106-111.

11. Geidam AD, Audu BM, Kawuwa BM , Obed JY (2009)Rising trend and indications of caesarean at Maiduguri hospital Nigeria. Ann Afr Med 8(2): 127-132.

12. Sharma A, Sharma U, Chaudary P, Acharya R, Chaudary A, et al. (2012) Maternal and neonatal outcome in patients with history of previous one ceasarean section. Indian Medical Gazette, pp. 169-173.

13. Lulu A, Noam A (1996) Outcome in elective and emergency caesarean sections: a comparative study. Annals of Saudi Medicine 6(6): 645-649.

14. Jarallah JS, Al Rubeaan KA, Al Nuaim AR, Al Ruhaily AA, Kalantan KA (1999) Prevalence and determinants of smoking in three regions of Saudi Arabia. Tob Control 8(1): 53-56.

15. Okezie A (2004) A 4-year analysis of caesarean delivery in a Nigerian teaching hospital: one-quarter of babies born surgically. Annals of African Medicine 3: 82-93.

16. Mohamed H (2006) The pattern of gynaecological and obstetrical admissions in Rabbit University Hospital, Khartuom. Sudan 's Journal of Public Health 1(2).

17. Gao Y, Qinqin X, Gang C, Peter S, Min Z, et al. (2013) Analysis of indications of $\mathrm{c} / \mathrm{s}$ in teaching Hospitals of china. European Journal of Obstetrics and Gynaecology and Reproductive Biology 170: 414-418.

18. Gessessew B, Barnabas GA, Prata N, Weidert K (2011) Task shifting and sharing in Tigray, Ethiopia, to achieve comprehensive emergency obstetric care. Int J Gynaecol Obstet 113(1): 28-31.

19. Archana S , Bukola F , James MM, Faouzi A, Jean José W (2009) Cesarean delivery outcomes from the WHO global survey on maternal and prenatal health in Africa-International Journal of Gynecology and Obstetrics 10: 56-81.predispose emergency CS will help in identifying pregnant women whoare at high risk for emergency CS and if possible, alter modifiable factors through education andanticipatory prevention, so as to prevent poor clinical outcomes.The results of this study will benefit hospitals, clinicians, and researchers in anticipatingmanagement of the mother and her child. It also aims to influence the decision-making amongclinicians, with the hope of decreasing maternal and neonatal morbidity and mortality, loweringpersonal and institutional health care costs.This study seeks to identify the common indications for emergency CS and will fill in the lack of local data on emergency CS and could provide a valuable contribution to national and international data 
Creative Commons Attribution 4.0 International License

\section{IGRWH Invesigations in Investigations in Gynecology Research \& Womens Health}

\section{Benefits of Publishing with us}

- High-level peer review and editorial services

- Freely accessible online immediately upon publication

- Authors retain the copyright to their work

- Licensing it under a Creative Commons license

- Visibility through different online platforms 